Article

\title{
Evaluation of Methods for Estimation of Cyclic Stress-Strain Parameters from Monotonic Properties of Steels
}

\author{
Tea Marohnić *, Robert Basan and Marina Franulović \\ Faculty of Engineering, University of Rijeka, Vukovarska 58, HR-51000 Rijeka, Croatia; \\ robert.basan@riteh.hr (R.B.); marina.franulovic@riteh.hr (M.F.) \\ * Correspondence: tmarohnic@riteh.hr; Tel.: +385-51-651-536 \\ Academic Editor: Filippo Berto \\ Received: 11 November 2016; Accepted: 30 December 2016; Published: 7 January 2017
}

\begin{abstract}
Most existing methods for estimation of cyclic yield stress and cyclic Ramberg-Osgood stress-strain parameters of steels from their monotonic properties were developed on relatively modest number of material datasets and without considerations of the particularities of different steel subgroups formed according to their chemical composition (unalloyed, low-alloy, and high-alloy steels) or delivery, i.e., testing condition. Furthermore, some methods were evaluated using the same datasets that were used for their development. In this paper, a comprehensive statistical analysis and evaluation of existing estimation methods were performed using an independent set of experimental material data compriseding 116 steels. Results of performed statistical analyses reveal that statistically significant differences exist among unalloyed, low-alloy, and high-alloy steels regarding their cyclic yield stress and cyclic Ramberg-Osgood stress-strain parameters. Therefore, estimation methods were evaluated separately for mentioned steel subgroups in order to more precisely determine their applicability for the estimation of cyclic behavior of steels belonging to individual subgroups. Evaluations revealed that considering all steels as a single group results in averaging and that subgroups should be treated independently. Based on results of performed statistical analysis, guidelines are provided for identification and selection of suitable methods to be applied for the estimation of cyclic stress-strain parameters of steels.
\end{abstract}

Keywords: estimation methods; monotonic properties; cyclic stress-strain parameters; Ramberg-Osgood; steel grouping; statistical analysis

\section{Introduction}

Development of computer technology and CAE software solutions have enabled performing complex simulations of material and product behavior under cyclic loading and fatigue life determination already during early stages of product development process. In recent years, rapid increases in computing power and availability of distributed and cloud-based resources have been seen. Within short time frame, complex simulations can be run for multiple materials. An example of these are strain-based, i.e., local strain-life fatigue, analyses which have been widely adopted in automotive, aeronautic, and power industry for fatigue life predictions of highly-loaded steel and aluminium components [1,2]. In order to perform these analyses, both cyclic stress-strain and strain-life fatigue curves and parameters that define them must be known. Well-accepted and widely used representation of stress-strain response of the majority of metallic materials is the cyclic Ramberg-Osgood (R-O) equation $[3,4]$ :

$$
\frac{\Delta \varepsilon}{2}=\frac{\Delta \varepsilon_{\mathrm{e}}}{2}+\frac{\Delta \varepsilon_{\mathrm{p}}}{2}=\frac{\Delta \sigma}{2 E}+\left(\frac{\Delta \sigma}{2 K^{\prime}}\right)^{\frac{1}{n^{\prime}}}
$$


For determination of lifetime in both low-cycle and high-cycle regime, Coffin-Manson-Basquin (C-M-B) $[4,5]$ approach is applied:

$$
\frac{\Delta \varepsilon}{2}=\frac{\Delta \varepsilon_{\mathrm{e}}}{2}+\frac{\Delta \varepsilon_{\mathrm{p}}}{2}=\frac{\sigma_{\mathrm{f}}^{\prime}}{E}\left(2 N_{\mathrm{f}}\right)^{b}+\varepsilon_{\mathrm{f}}^{\prime}\left(2 N_{\mathrm{f}}\right)^{c}
$$

In Equations (1) and (2) $\Delta \varepsilon, \Delta \varepsilon_{\mathrm{e}}$ and $\Delta \varepsilon_{\mathrm{p}}$ are true total, elastic and plastic strain ranges, respectively, $\Delta \sigma$ is true stress range, $E$ is Young's modulus, $K^{\prime}$ is cyclic strength coefficient, and $n^{\prime}$ is cyclic strain hardening exponent. Furthermore, $\sigma_{\mathrm{f}}{ }^{\prime}, \varepsilon_{\mathrm{f}}{ }^{\prime}, b$ and $c$ are fatigue strength and ductility parameters obtained from fully reversed tension-compression fatigue tests.

Cyclic R-O and C-M-B parameters obtained through material testing are most accurate, but are very often unavailable due to long time and high costs associated with experimental characterization. Existing test results which are available in literature and materials databases often do not sufficiently correspond to the actual material under consideration. Hence, it has become common practice to estimate cyclic R-O and C-M-B parameters of the material from its monotonic properties early during product development. For estimation of C-M-B fatigue parameters from monotonic properties of materials, many methods have been developed [5-8] and evaluated in literature [9]. To the contrary, for estimation of cyclic R-O parameters of materials, only a limited number of methods are proposed [10-13]. For estimations of cyclic yield stress $R_{\mathrm{e}}{ }^{\prime}$ and R-O parameters $\left(K^{\prime}\right.$ and $\left.n^{\prime}\right)$ various monotonic properties and their combinations are used, with ultimate strength $R_{\mathrm{m}}$ and yield stress $R_{\mathrm{e}}$ being the most common since they are readily available. Detailed overview of monotonic properties used for estimation of cyclic parameters of metallic materials and systematic study of their relevance for estimation purposes is provided in [14].

No independent and systematic evaluations of these methods can be found in the literature, the only ones available being those performed in respective papers where methods were proposed.

The main aim of this paper is to provide detailed analysis and evaluation of existing methods for estimation of cyclic yield stress $R_{\mathrm{e}}{ }^{\prime}$ and cyclic stress-strain parameters $K^{\prime}$ and $n^{\prime}$ from monotonic properties. For this purpose, a large and independent set of material data was collected from relevant sources. Since previous investigations [15-17] confirmed that dividing steels into different subgroups might improve estimation accuracy, this will also be taken into consideration. One-way Analysis of Variance (one-way ANOVA) and post hoc Tukey's test will be performed in order to check whether individual steel groups are statistically different regarding their cyclic parameters $R_{\mathrm{e}}{ }^{\prime}, K^{\prime}$ and $n^{\prime}$. If such differences are confirmed to exist, in addition to evaluation of existing methods for all steels together, partial evaluations for each steel subgroup will be performed as well.

\section{Overview of Existing Methods for Estimation of Cyclic Stress-Strain Parameters}

\subsection{Methods for Estimation of Cyclic Yield Stress $R_{e}^{\prime}$}

Li et al. [11] originally proposed estimation of cyclic yield stress $R_{\mathrm{e}}{ }^{\prime}$ of steels from ultimate strength $R_{\mathrm{m}}$ and reduction of area at fracture $R A$. Equation (3) was developed using monotonic and cyclic properties of 27 , mostly unalloyed and low-alloy steels:

$$
R_{\mathrm{e}}^{\prime}=(1+R A) R_{\mathrm{m}}\left(-\frac{0.002}{\ln (1-R A)}\right)^{0.16}
$$

Evaluation of proposed expression is performed on the same data used for developing the method, and is reported that estimated values of $R_{\mathrm{e}}{ }^{\prime}$ deviate at most $14 \%$ from their experimental counterparts.

Lopez and Fatemi [12] developed a number of relationships between Brinell hardness (HB or monotonic properties and cyclic yield stress $R_{\mathrm{e}}{ }^{\prime}$ of steels. These were developed and validated on a relatively large number of steels consisting mostly of unalloyed and low-alloy steels, covering a wide variation of chemical composition and mechanical properties, with ultimate stress $R_{\mathrm{m}}$ ranging from 279 to $2450 \mathrm{MPa}$ and hardness from 80 to $595 \mathrm{HB}$. Materials were divided according to ultimate 
strength to yield stress ratio $R_{\mathrm{m}} / R_{\mathrm{e}}$, since it was shown that such division improves the accuracy of cyclic parameters estimation. Ratio $R_{\mathrm{m}} / R_{\mathrm{e}}$ was originally proposed by Smith et al. [18] to be used for prediction of cyclic behavior (hardening, softening, stable behavior) of materials. Correspondingly, authors proposed a number of separate expressions for estimation of $R_{\mathrm{e}}{ }^{\prime}$ depending on value of $R_{\mathrm{m}} / R_{\mathrm{e}}$ of which the most successful ones are:

$$
\begin{gathered}
R_{\mathrm{e}}^{\prime}=0.75 R_{\mathrm{e}}+82 \text { for } R_{\mathrm{m}} / R_{\mathrm{e}}>1.2 \\
R_{\mathrm{e}}^{\prime}=3.0 \times 10^{-4} R_{\mathrm{e}}^{2}-0.15 R_{\mathrm{e}}+526 \text { for } R_{\mathrm{m}} / R_{\mathrm{e}} \leq 1.2
\end{gathered}
$$

Additionally, single expression for all steels, regardless of the value of $R_{\mathrm{m}} / R_{\mathrm{e}}$ is also proposed:

$$
R_{\mathrm{e}}^{\prime}=8.0 \times 10^{-5} R_{\mathrm{m}}^{2}+0.54 R_{\mathrm{m}}
$$

Values of coefficient of determination $R^{2}$ for expressions (4a), (4b) and (5) were $0.88,0.99$, and 0.94 respectively. Evaluation was performed on a single dataset comprising data used for developing expressions and additional data (all together 121 materials, mostly unalloyed and low-alloy steels). It was established that $84 \%$ of estimated values of $R_{\mathrm{e}}{ }^{\prime}$ from yield stress $R_{\mathrm{e}}$ (Equations (4a) and (4b)) deviate up to $\pm 20 \%$ from experimental values while $79 \%$ of values of $R_{\mathrm{e}}{ }^{\prime}$ estimated from ultimate strength $R_{\mathrm{m}}$ (Equation (5)) deviated up to $\pm 20 \%$ from experimental values.

Motivated by findings from [12] that Equation (3) always underestimates cyclic yield stress $R_{\mathrm{e}}{ }^{\prime}$ when experimental value of $R_{\mathrm{e}}{ }^{\prime}$ exceeds $900 \mathrm{MPa}$, Li et al. [13] recently modified Equation (3) to:

$$
R_{\mathrm{e}}^{\prime}=0.089(1+R A)^{1.35} R_{\mathrm{m}}^{1.35} \times\left(-\frac{0.002}{\ln (1-R A)}\right)^{0.216}+120
$$

resulting in rather high coefficient of determination $R^{2}=0.961$. Analysis was performed on the majority of data used in [12]. For evaluation, data used for developing Equation (6) was complemented with additional data. Results showed that most values of $R_{\mathrm{e}}{ }^{\prime}$ estimated from Equation (6) deviate up to $20 \%$ from their experiment-based counterparts. It must be noted that [11] and [13] suggest that values of true fracture strength $\sigma_{\mathrm{f}}$ can be calculated using the expression:

$$
\sigma_{\mathrm{f}}=R_{\mathrm{m}}(1+R A)
$$

which is recognizable as first part of Equations (3) and (6). However, a well-known approximation of the relationship between ultimate strength $R_{\mathrm{m}}$ and true fracture stress $\sigma_{\mathrm{f}}$, recommended by Manson [5,9] is:

$$
\sigma_{\mathrm{f}}=R_{\mathrm{m}}\left(1+\varepsilon_{\mathrm{f}}\right)
$$

Therefore, caution is advised when applying expressions (3) and (6) for estimation of not only cyclic yield stress $R_{\mathrm{e}}{ }^{\prime}$, but also cyclic parameters $K^{\prime}$ and $n^{\prime}$ that will be discussed later in Section 2.2.

\subsection{Methods for Estimation of Cyclic Parameters $K^{\prime}$ and $n^{\prime}$}

Zhang et al. [10] proposed several equations for estimation of $K^{\prime}$ and $n^{\prime}$ based on 22 steels, aluminium (Al), and titanium (Ti) alloys. For this purpose, materials were divided by value of so-called new fracture ductility parameter $\alpha$ :

$$
\alpha_{\mathrm{f}}=R A \times \varepsilon_{\mathrm{f}}=-R A \ln (1-R A)
$$

proposed in [19]. Expressions were proposed for estimation of $K^{\prime}$ and $n^{\prime}$, Equation (10) through Equation (11c), when strength coefficient $K$ and strain hardening exponent $n$ are available:

$$
K^{\prime}=57 K^{0.545}-1220
$$




$$
\begin{gathered}
n^{\prime}=1.06 n\left(1+\beta\left|1-\frac{R_{\mathrm{m}}}{R_{\mathrm{p} 0.2}}\right|\right) \text { for } \alpha<5 \% \text { or } 10 \% \leq \alpha<20 \% \\
n^{\prime}=1.06 n\left(1+\beta\left|1-\frac{\sigma_{\mathrm{f}}}{R_{\mathrm{m}}}\right|\right) \text { for } 5 \%<\alpha<10 \% \\
n^{\prime}=\frac{R_{\mathrm{p} 0.2}}{\sigma_{\mathrm{f}}-R_{\mathrm{m}}} n \text { for } \alpha>20 \%
\end{gathered}
$$

and Equation (12a) through Equation (13c) when $K$ and $n$ are not available:

$$
\begin{aligned}
& K^{\prime}=57\left(\sigma_{\mathrm{f}} \varepsilon_{\mathrm{f}}^{-\frac{\log \left(\frac{R_{\mathrm{m}}^{2} \sigma_{\mathrm{f}}{ }^{3}}{\left.R_{p 0.2^{5}}\right)}\right.}{3 \log \left(500 \varepsilon_{\mathrm{f}}\right)}}\right)^{0.545}-1220 \text { for } \alpha<5 \% \text { or } 10 \% \leq \alpha<20 \% \\
& K^{\prime}=57\left(\frac{\sigma_{\mathrm{f}} R_{\mathrm{p} 0.2}}{R_{\mathrm{m}}} \varepsilon_{\mathrm{f}}^{-\frac{\log \left(\frac{\sigma_{\mathrm{f}}{ }^{2}}{R_{\mathrm{p} 0.2} R_{\mathrm{m}}}\right)}{2 \log \left(500 \varepsilon_{\mathrm{f}}\right)}}\right)^{0.545}-1220 \text { for } 5 \%<\alpha<10 \% \text { or } \alpha>20 \% \\
& n^{\prime}=1.06\left(1+\beta\left|1-\frac{R_{\mathrm{m}}}{R_{\mathrm{p} 0.2}}\right|\right) \frac{\log \left(\frac{R_{\mathrm{m}}^{2} \sigma_{\mathrm{f}}^{3}}{R_{\mathrm{p} 0.2}{ }^{5}}\right)}{3 \log \left(500 \varepsilon_{\mathrm{f}}\right)} \text { for } \alpha<5 \% \text { or } 10 \% \leq \alpha<20 \% \\
& n^{\prime}=1.06\left(1+\beta\left|1-\frac{\sigma_{\mathrm{f}}}{R_{\mathrm{m}}}\right|\right) \frac{\log \left(\frac{\sigma_{\mathrm{f}}^{2}}{R_{\mathrm{p} 0.2} R_{\mathrm{m}}}\right)}{2 \log \left(500 \varepsilon_{\mathrm{f}}\right)} \text { for } 5 \%<\alpha<10 \% \\
& n^{\prime}=\frac{R_{\mathrm{p} 0.2}}{\sigma_{\mathrm{f}}-R_{\mathrm{m}}} \frac{\log \left(\frac{\sigma_{\mathrm{f}}^{2}}{R_{\mathrm{p} 0.2} R_{\mathrm{m}}}\right)}{2 \log \left(500 \varepsilon_{\mathrm{f}}\right)} \text { for } \alpha>20 \%
\end{aligned}
$$

For both methods, parameter $\beta=1$ for $\sigma_{\mathrm{f}} / R_{\mathrm{p} 0.2}<1.6$ and $\beta=-1$ for $\sigma_{\mathrm{f}} / R_{\mathrm{p} 0.2}>1.6$. As most successful expressions authors proposed estimation of $K^{\prime}$ based on strength coefficient $K$ (Equation (10)) and estimation of $n^{\prime}$ based on ultimate strength $R_{\mathrm{m}}$, yield stress $R_{\mathrm{e}}$, true fracture stress $\sigma_{\mathrm{f}}$ and strain hardening exponent $n$ (Equation (13a) through Equation (13c), depending on value of $\alpha$ ). For steels, values of $K^{\prime}$ and $n^{\prime}$ estimated in such a way deviated up to $27 \%$ and $34 \%$, respectively, from their experiment-based counterparts. Data tables with percentage deviation for aluminium and titanium alloys suggest even larger deviations of estimates of $n^{\prime}$ (up to 65\%). They also suggested that, for stress amplitudes $\Delta \sigma / 2$ calculated from estimated values of $K^{\prime}$ and $n^{\prime}$, besides percentage deviation of particular parameter, sign of deviation is also significant. If sign of deviations of $K^{\prime}$ and $n^{\prime}$ is the same, calculated and experimental cyclic stress-strain curves are in good agreement.

In [12], besides expressions for estimation of $R_{\mathrm{e}}{ }^{\prime}$, Lopez and Fatemi developed several relationships between Brinell hardness $H B$ or monotonic properties and cyclic parameters $K^{\prime}$ and $n^{\prime}$ of steels. Steels are divided into two subgroups according to the value of the $R_{\mathrm{m}} / R_{\mathrm{e}}$ ratio (as was the case for estimation of cyclic yield stress $R_{\mathrm{e}}{ }^{\prime}$ ) and different expressions are proposed accordingly. Equations (14a) and (14b) are denoted as most successful:

$$
\begin{gathered}
K^{\prime}=1.16 R_{\mathrm{m}}+593 \text { for } R_{\mathrm{m}} / R_{\mathrm{e}}>1.2 \\
K^{\prime}=3.0 \cdot 10^{-4} R_{\mathrm{m}}^{2}+0.23 R_{\mathrm{m}}+619 \text { for } R_{\mathrm{m}} / R_{\mathrm{e}} \leq 1.2 \\
n^{\prime}=-0.37 \log \left(\frac{0.75 R_{e}+82}{1.16 R_{\mathrm{m}}+593}\right) \text { for } R_{\mathrm{m}} / R_{\mathrm{e}}>1.2 \\
n^{\prime}=-0.37 \log \left(\frac{3.0 \times 10^{-4} R_{\mathrm{e}}^{2}-0.15 R_{\mathrm{e}}+526}{3.0 \times 10^{-4} R_{\mathrm{m}}^{2}+0.23 R_{\mathrm{m}}+619}\right) \text { for } R_{\mathrm{m}} / R_{\mathrm{e}} \leq 1.2
\end{gathered}
$$


Authors provided coefficients of determination $R^{2}$ only for expressions (14a) and (14b). It is worth noting that $R^{2}$ of expressions proposed for estimation of $K^{\prime}$ for steels with $R_{\mathrm{m}} / R_{\mathrm{e}}>1.2$ is 0.75 which is significantly lower than 0.90 obtained for steels with $R_{\mathrm{m}} / R_{\mathrm{e}} \leq 1.2$. About $73 \%$ values of $K^{\prime}$ estimated using Equations (14a) and (14b) deviate less than $\pm 20 \%$ from their experimental values. As for $n^{\prime}$, percentage of values estimated from Equations (15a) and (15b) that deviate less than $\pm 20 \%$ from their experiment-based counterparts is around $60 \%$.

Lopez and Fatemi [12] proposed additional expression for estimation of $n^{\prime}$ valid for all steels:

$$
n^{\prime}=-0.33\left(R_{e} / R_{\mathrm{m}}\right)+0.40
$$

for which $R^{2}$ obtained was 0.79. Percentage of values of $n^{\prime}$ estimated from Equation (16) that deviated up to $\pm 20 \%$ from experimental values was $68 \%$.

Both methods proposed in [12] for estimation of $n^{\prime}$ provide reasonably good results, so in further evaluations in this paper, both methods will be taken into account: first using Equation (14a) through Equation (15b), and second using Equations (14a), (14b) and (16).

Li et al. [13] proposed expressions for estimation of cyclic parameters $K^{\prime}$ and $n^{\prime}$ :

$$
\begin{gathered}
K^{\prime}=500^{n^{\prime}} R_{\mathrm{e}}^{\prime} \\
n^{\prime}=\frac{\log \left(K^{\prime}\right)-\log \left(R_{\mathrm{e}}^{\prime}\right)}{\log 500}
\end{gathered}
$$

where $R_{\mathrm{e}}{ }^{\prime}$ is estimated using Equation (6). However, Equations (17) and (18) can be used only when either $K^{\prime}$ or $n^{\prime}$ are available, so in the same paper an alternative method for estimation of these parameters was proposed. Cyclic strength coefficient $K^{\prime}$ should be estimated using Equations (19a), $(19 b)$ or (19c) first, then cyclic strain hardening $n^{\prime}$ exponent is calculated from estimated values of $K^{\prime}$.

$$
\begin{gathered}
K^{\prime}=2.16 \cdot 10^{-4}\left(R_{\mathrm{m}}\right)^{2.1}+738 \text { for } R_{\mathrm{m}} / R_{\mathrm{e}} \leq 1.2 \\
K^{\prime}=3.63 \cdot 10^{-4}\left(R_{\mathrm{m}}\right)^{2}+0.68 R_{\mathrm{m}}+570 \text { for } 1.2<R_{\mathrm{m}} / R_{\mathrm{e}}<1.4 \\
K^{\prime}=1.21 R_{\mathrm{m}}+555 \text { for } R_{\mathrm{m}} / R_{\mathrm{e}} \geq 1.4
\end{gathered}
$$

Equation (19a) through Equation (19c), when used in combination with Equation (18), yielded reasonable results with most of estimated values of $K^{\prime}$ deviating up to $\pm 20 \%$ from experimental values. Obtained coefficients of determination $R^{2}$ for Equation (19a) through Equation (19c) decrease with higher values of $R_{\mathrm{m}} / R_{\mathrm{e}}$, which is in accordance with findings from [12]. $R^{2}$ obtained for steels with $R_{\mathrm{m}} / R_{\mathrm{e}} \leq 1.2$ is 0.921 , while for steels with $1.2<R_{\mathrm{m}} / R_{\mathrm{e}}<1.4$ and $R_{\mathrm{m}} / R_{\mathrm{e}} \geq 1.4$ coefficients of determination are $R^{2}=0.813$ and $R^{2}=0.712$, respectively. Again, caution is advised when using Equation (18) due to the suggested way of estimating $R_{\mathrm{e}}{ }^{\prime}$ that was already discussed at the end of Section 2.1.

\subsection{Conclusions}

A review of methods for estimation cyclic parameters shows that sets of material data on which most of them were developed and evaluated differ significantly regarding their size and material groups included. In this sense, they can still be considered adequate with the exception of expressions for estimation of $K^{\prime}$ and $n^{\prime}$ proposed in [10] which were developed using a quite small and heterogeneous set of material data (22 datasets for steels, aluminium and titanium alloys) and expression for estimation of $R_{\mathrm{e}}{ }^{\prime}$ proposed in [10] which was developed using only 27 steel datasets.

In an attempt to further improve estimation accuracy, most methods address steels separately from other kinds of metallic materials [11-13] and all methods divide materials into separate subgroups using different criteria [10,12,13]. For this purpose, Zhang et al. [10] used new fracture ductility parameter $\alpha$ that was originally developed to predict materials' cyclic behavior [10,19]. Lopez and 
Fatemi [12] and Li et al. [13] divided steels into two, i.e., three subgroups according to the ratio of ultimate strength to yield stress $R_{\mathrm{m}} / R_{\mathrm{e}}$.

Lack of general consensus regarding the treatment of individual material subgroups as well as different methodologies for evaluation of estimation methods implemented in their respective papers makes comparison of their performance quite difficult. In order to determine which estimation method is most suitable for estimation of cyclic parameters of steels, systematic and consistent evaluation of presented methods will be performed on an independent set of material data.

Different delivery, i.e., testing conditions of material, can be obtained for example through different processing method or heat treatment and this can strongly impact both monotonic and cyclic/fatigue material properties and behavior [5,20]. This is an important aspect which none of the discussed methods takes into account directly. One of the possible reasons is a multitude of conditions of steel materials which were used for development of these methods, particularly in [12,13]. For certain materials, such information, even if available, was of a rather general nature (for example heat treated, modified, etc.).

In practice, steels are commonly divided according to the content of alloying elements into unalloyed, low-alloy and high-alloy steels. Already Baümel and Seeger [6] considered unalloyed and low-alloy steels separately from other metallic materials when they developed Uniform Material Law for estimation of C-M-B parameters. Hatscher et al. [8] also mentioned the prospect of such division for estimation of fatigue C-M-B parameters. Results of detailed analysis performed on a large number of material data done by Basan et al. [15] showed that there is statistically significant difference among individual C-M-B fatigue parameters as well as strain-life behavior $\left(\Delta \varepsilon-2 N_{\mathrm{f}}\right.$ relationships) of unalloyed, low-alloy and high-alloy steels. Also, preliminary investigations on cyclic parameters in $[16,17]$ showed that dividing steels by alloying content could result in more accurate estimations of cyclic parameters and hence, more accurate estimations of cyclic stress-strain curves of materials.

For that reason, statistical analysis of steel subgroups (unalloyed, low-alloy and high-alloy steels) will be performed in order to determine if their cyclic parameters differ significantly. If confirmed, individual steel subgroups will be taken into account during evaluation and comparison of estimation methods.

\section{Methods and Data}

\subsection{Methods for Statistical Analysis}

To test whether statistically significant differences exist among experimental data for cyclic yield stress $R_{\mathrm{e}}{ }^{\prime}$ and cyclic stress-strain parameters $K^{\prime}$ and $n^{\prime}$ of unalloyed, low-alloy and high-alloy steels, one-way Analysis of Variance (one-way ANOVA) is performed. One-way ANOVA is a technique that provides a statistical test of whether or not means of several (typically three or more) groups are all equal. If results obtained by one-way ANOVA show that statistically significant difference exists between cyclic parameters of analyzed groups, post hoc analysis by Tukey's multiple comparison method will be performed in order to determine pairwise differences between groups. Significance level $\alpha$ for one-way ANOVA is set to 0.05 , while overall significance (family error rate) in Tukey's multiple comparison test is set to 0.05 to counter type I error for a series of comparisons. Procedure for both one-way ANOVA and Tukey's multiple comparison test are given in [21]. Statistical analyses were performed in statistical package MINITAB [22].

To evaluate predictive accuracy of estimation methods and to facilitate their comparison, deviations of estimated values from their experimentally obtained counterparts were used as relevant indicators. Deviations up to $\pm 10, \pm 20$ and $\pm 30 \%$ were used as in $[12,13]$ to facilitate comparison with results reported there. Instead of directly comparing estimated Ramberg-Osgood parameters $K^{\prime}$ and $n^{\prime}$ to their experiment-based counterparts as in [12,13], much more useful information regarding the predictive accuracy of these methods can be obtained by comparing values of stress amplitudes $\Delta \sigma / 2$, i.e., points on cyclic stress-strain curves as in $[10,16,17]$. Therefore, values of stress amplitudes $\Delta \sigma / 2$ 
were calculated using experimental values of $K^{\prime}$ and $n^{\prime}$ and their estimations for series of total strain amplitudes $\Delta \varepsilon / 2: 0.1,0.2,1$ and $2 \%$.

\subsection{Data to Be Analyzed}

Experimental data for three representative groups of steels: unalloyed (UA), low-alloy (LA) and high-alloy (HA) steels from [6] and [23] were obtained through the MATDAT Materials Properties Database [24]. Only results of strain-controlled, fully reversed $(R=-1)$ axial cyclic tests performed in the air at room temperature were considered. Furthermore, only data for materials tested at more than four different strain amplitudes and at range of total strain amplitudes larger than $0.4 \%$ were used in the analysis.

Only datasets that contained all experimental values of monotonic properties needed for estimation of cyclic parameters by each method were used. An exception was made with the high-alloy steel group. Since most datasets did not contain values of true fracture stress $\sigma_{\mathrm{f}}$ which is necessary for calculation of parameters by Zhang et al. method [10], values were calculated by their relationship between ultimate strength $R_{\mathrm{m}}$ and true fracture strain $\varepsilon_{\mathrm{f}}$, according to Equation (8). Also, if a dataset contained only reduction of area at fracture $R A$, true fracture strain $\varepsilon_{\mathrm{f}}$ was calculated by the relationship between these two properties:

$$
\varepsilon_{\mathrm{f}}=-\ln (1-R A)
$$

In total, 34 unalloyed steels, 47 low-alloy steels and 35 high-alloy steel datasets were available for analysis. Wide variety of conditions resulting from different processing and heat treatment were present in materials used for statistical analysis and evaluation of existing methods. This is consistent with datasets used for development of methods in their respective papers.

Detailed material data are given in Appendix A in Tables A1-A3. Data used for statistical analysis in [14] were complemented with values of true fracture strain $\varepsilon_{f}$. Additionally, data for high-alloy steels were complemented with values of true fracture stress $\sigma_{\mathrm{f}}$, strength coefficient $K$ and strain hardening exponent $n$ since those are required so that evaluations of particular existing methods could be performed.

\section{Analysis and Results}

\subsection{Results of One-Way ANOVA and Tukey's Multiple Comparison Test}

Performing one-way ANOVA for three cyclic parameters $\left(R_{\mathrm{e}}{ }^{\prime}, K^{\prime}\right.$ and $\left.n^{\prime}\right)$ of unalloyed, lowand high-alloy steel subgroups showed that statistically significant differences exist between steel subgroups regarding cyclic yield stress $R_{\mathrm{e}}{ }^{\prime}(F(2,113)=32.25 ; p<0.05)$, cyclic strength coefficient $K^{\prime}$ $(F(2,113)=22.61 ; p<0.05)$, and cyclic strain hardening exponent $n^{\prime}(F(2,113)=72.00 ; p<0.05)$.

Since steel subgroups were confirmed to be significantly different regarding their cyclic parameters $R_{\mathrm{e}}{ }^{\prime}, K^{\prime}$ and $n^{\prime}$, post hoc Tukey's test was performed to determine which subgroups are mutually different. Results showed that unalloyed and low-alloy steels as well as low-alloy and high-alloy steels differ significantly regarding the cyclic yield stress $R_{\mathrm{e}}{ }^{\prime}$. No such difference was determined between unalloyed and high-alloy steels. Statistically significant difference was also found for cyclic strength coefficient $K^{\prime}$ of unalloyed and high-alloy steels, as well as low-alloy and high-alloy steels, while no such difference was found between unalloyed and low-alloy steels. Cyclic strain hardening exponent $n^{\prime}$ differs between pairs of all three groups.

\subsection{Evaluation of Methods for Estimation of Cyclic Yield Stress $R_{e}{ }^{\prime}$ and Ramberg-Osgood Parameters $K^{\prime}$ and $n^{\prime}$ of Steels}

Since unalloyed, low-alloy and high-alloy steels subgroups were proved to be significantly different, steel subgroups will be considered separately for evaluation of estimation methods. Evaluation will also be made for all steels as a single group to check for differences between results of 
analyses performed on individual subgroups and to enable comparison and determination of potential discrepancies with results reported in original papers.

Methods for estimation of cyclic yield stress $R_{\mathrm{e}}{ }^{\prime}$ and R-O parameters $K^{\prime}$ and $n^{\prime}$ of steels whose predictive accuracy will be evaluated are listed in Table 1 . For every material, expressions for estimation of cyclic yield stress $R_{\mathrm{e}}{ }^{\prime}$ and R-O parameters $K^{\prime}$ and $n^{\prime}$ will be used according to ranges defining the applicability of the models regarding criteria for grouping of materials in original papers (new fracture ductility coefficient $\alpha$, ultimate strength to yield stress ratio $R_{\mathrm{m}} / R_{\mathrm{e}}$ ).

\subsubsection{Evaluation of Methods for Estimation of Cyclic Yield Stress $R_{\mathrm{e}}{ }^{\prime}$}

Percentages of values of $R_{\mathrm{e}}{ }^{\prime}$ estimated according to selected methods (Table 1) that deviate up to $10 \%, 20 \%$ and up to $30 \%$ from experiment-based values were calculated and are given in diagrams on Figure 1.

Table 1. Methods for estimation of $R_{\mathrm{e}}{ }^{\prime}$ and $K^{\prime}$ and $n^{\prime}$ which will be evaluated.

\begin{tabular}{|c|c|c|c|c|}
\hline $\begin{array}{l}\text { Evaluated } \\
\text { Value }\end{array}$ & Method & $\begin{array}{c}\text { Estimated } \\
\text { Parameters }\end{array}$ & Originally Proposed for & $\begin{array}{l}\text { Equation } \\
\text { Number }\end{array}$ \\
\hline \multirow{3}{*}{$R_{\mathrm{e}}{ }^{\prime}$} & Lopez and Fatemi 1 [12] & $R_{\mathrm{e}}^{\prime}$ & steels divided by $R_{\mathrm{m}} / R_{\mathrm{e}}$ & $(4 a, b)$ \\
\hline & Lopez and Fatemi 2 [12] & $R_{\mathrm{e}}^{\prime}$ & all steels & $(5)$ \\
\hline & Li et al. [13] & $R_{\mathrm{e}}^{\prime}$ & all steels & (6) \\
\hline \multirow{10}{*}{$\Delta \sigma / 2$} & Zhang et al. 1 [10] & $K^{\prime}$ & steels, $\mathrm{Al}$ and $\mathrm{Ti}$ alloys & $(10)$ \\
\hline & ( $K$ and $n$ available) & $n^{\prime}$ & steels, $\mathrm{Al}$ and $\mathrm{Ti}$ alloys divided by $\alpha$ & $(11 a, b, c)$ \\
\hline & Zhang et al. 2 [10] & $K^{\prime}$ & steels, $\mathrm{Al}$ and $\mathrm{Ti}$ alloys divided by $\alpha$ & $(12 a, b)$ \\
\hline & ( $K$ and $n$ not available) & $n^{\prime}$ & steels, $\mathrm{Al}$ and $\mathrm{Ti}$ alloys divided by $\alpha$ & $(13 a, b, c)$ \\
\hline & \multirow{2}{*}{ Lopez and Fatemi 1 [12] } & $K^{\prime}$ & steels divided by $R_{\mathrm{m}} / R_{\mathrm{e}}$ & $(14 a, b)$ \\
\hline & & $n^{\prime}$ & steels divided by $R_{\mathrm{m}} / R_{\mathrm{e}}$ & $(15 a, b)$ \\
\hline & \multirow{2}{*}{ Lopez and Fatemi 2 [12] } & $K^{\prime}$ & steels divided by $R_{\mathrm{m}} / R_{\mathrm{e}}$ & $(14 a, b)$ \\
\hline & & $n^{\prime}$ & all steels & (16) \\
\hline & \multirow{2}{*}{ Li et al. [13] } & $K^{\prime}$ & steels divided by $R_{\mathrm{m}} / R_{\mathrm{e}}$ & $(19 a, b, c)$ \\
\hline & & $n^{\prime}$ & steels divided by $R_{m} / R_{\mathrm{e}}$ & (18) \\
\hline
\end{tabular}

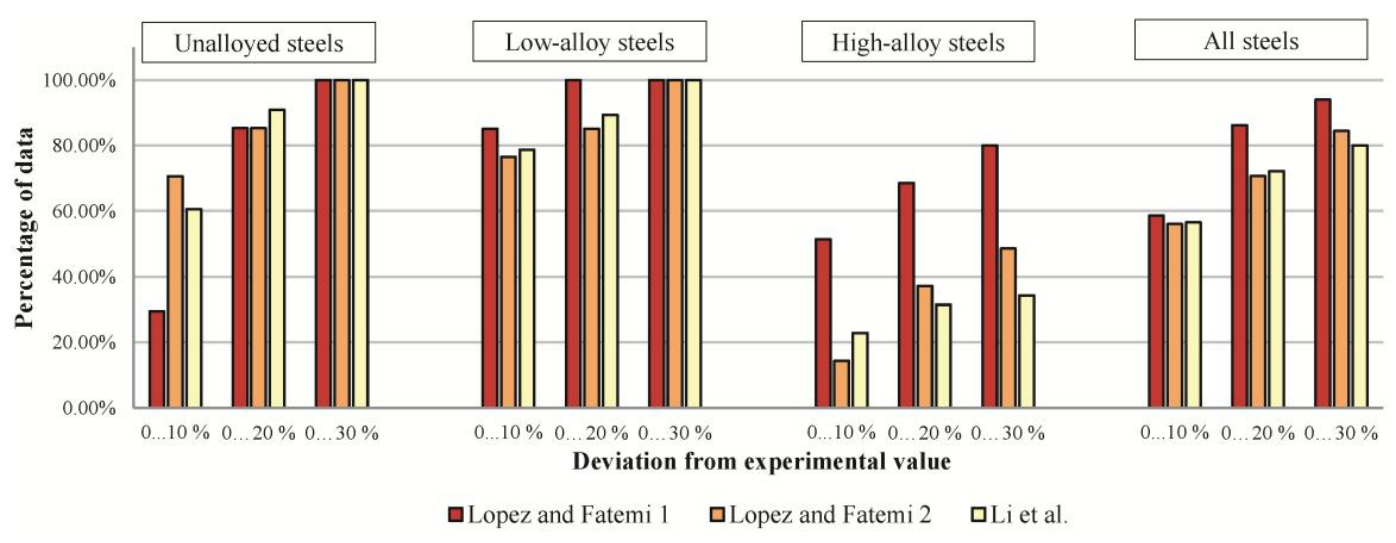

Figure 1. Percentage of $R_{\mathrm{e}}{ }^{\prime}$ values estimated by selected methods that deviate up to $10 \%, 20 \%$ and $30 \%$ from experiment-based values.

Reasonable results are obtained for All steels group with about $70 \%-80 \%$ of data deviating up to $20 \%$ from their experimental counterparts for each method.

For unalloyed steels, for each method about $80 \%-90 \%$ of estimates of cyclic yield stress $R_{\mathrm{e}}{ }^{\prime}$ deviate up to $20 \%$, while all estimates fall within $\pm 30 \%$ deviation from corresponding experimental values. Highest percentage of data that deviate only up to $10 \%$ is obtained by Lopez and Fatemi 2 (about $70 \%$ ).

For low-alloy steels, results obtained using any of the three selected methods were even more accurate than for unalloyed steels. Best results for estimation of $R_{\mathrm{e}}{ }^{\prime}$ of low-alloy steels are obtained using Lopez and Fatemi 1 method, for which all estimates deviate 20\% or less from their experiment-based counterparts. 
As for high-alloy steels, no method proved to be sufficiently accurate. Lopez and Fatemi 1 provides reasonable results with about $70 \%$ of estimated data deviating up to $20 \%$, although $20 \%$ of data deviate more than $30 \%$ from experimental values. Estimations made by other two methods result with less than $50 \%$ of estimates deviating below 30\% from experimental values (below $40 \%$ by Li et al.).

\subsubsection{Evaluation of Methods for Estimation of Ramberg-Osgood Parameters $K^{\prime}$ and $n^{\prime}$ of Steels}

As was explained in Section 3.1, accuracy of estimates of Ramberg-Osgood parameters $K^{\prime}$ and $n^{\prime}$ will be determined by evaluating values of stress amplitudes $\Delta \sigma / 2$ calculated using estimated $K^{\prime}$ and $n^{\prime}$ opposed to those obtained using experimental values of those parameters.

Percentages of estimated values of $\Delta \sigma / 2$ as calculated by selected methods (Table 1) that deviate up to $10 \%, 20 \%$ and up to $30 \%$ from experiment-based values are given in Figure 2 .

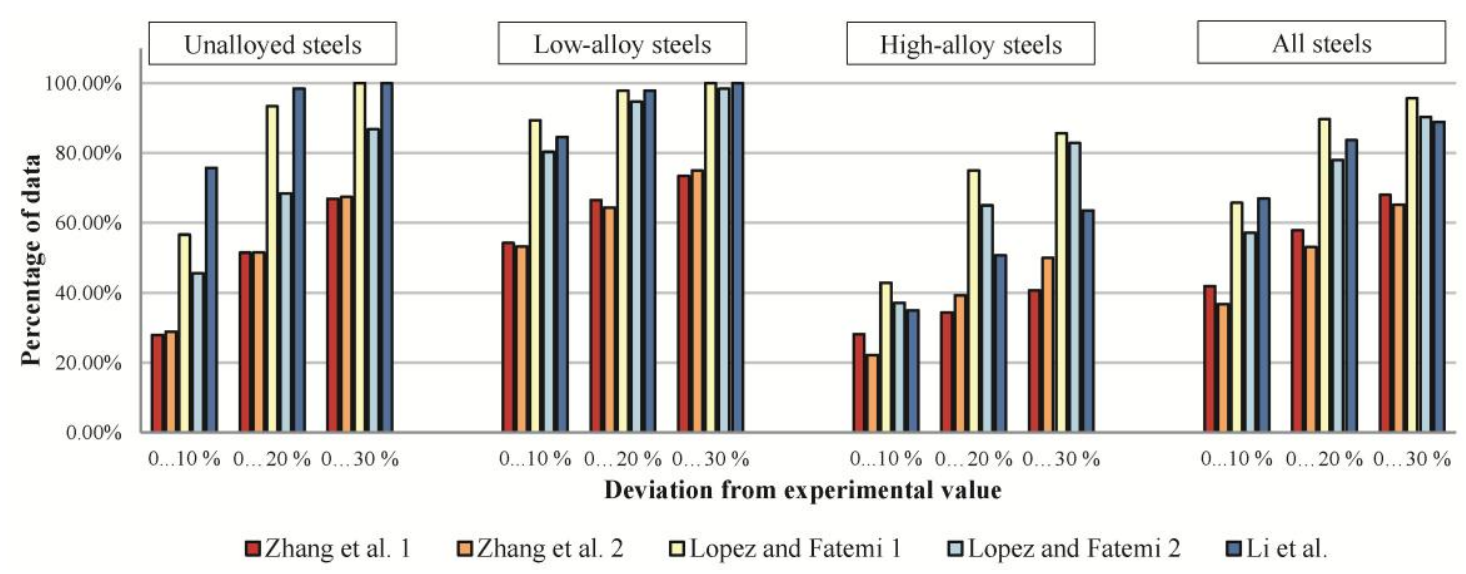

Figure 2. Percentage of $\Delta \sigma / 2$ values estimated by selected methods that deviate up to $10 \%, 20 \%$ and $30 \%$ from experiment-based values.

Results obtained using Lopez and Fatemi 1 and Li et al. method for estimation of $K^{\prime}$ and $n^{\prime}$ both provide very good results for estimation of stress amplitudes $\Delta \sigma / 2$ of unalloyed steels, with over $90 \%$ of data deviating $20 \%$ or less from experimental values. For both methods, all estimates of $\Delta \sigma / 2$ for unalloyed steels fall within $\pm 30 \%$ deviation from experimental values, with Li et al. method providing as much as $75 \%$ of data within $\pm 10 \%$ deviation.

The same methods yield even better results for low-alloy steels, with more than $80 \%$ of data deviating up to $10 \%$ from experiment-based counterparts. Although somewhat less accurate than previous two, Lopez and Fatemi 2 method also provides very good results for estimation of $\Delta \sigma / 2$ of low-alloy steels.

Both methods by Zhang et al. gave significantly inferior results for both unalloyed and low-alloy steel subgroups. For unalloyed steels, by either method, only about $50 \%$ of data deviate $20 \%$ or less from experimental values, while about one-third of data deviate more than $30 \%$ from corresponding experimental values. Results are somewhat better for low-alloy steels, with a higher percentage of data deviating $20 \%$ or less from experimental values (about $65 \%$ ). Still, only $75 \%$ of estimates obtained using both methods by Zhang et al. deviate less than $30 \%$ from experimental values.

As for high-alloy steels, no method provided estimates on the level of accuracy observed for unalloyed and low-alloy steels. Results obtained using either method by Lopez and Fatemi are the most acceptable, with around $75 \%$ of values estimated using Lopez and Fatemi 1 deviating less than $20 \%$. Estimations by Li et al. resulted in more than $35 \%$ of data deviating more than $30 \%$ from experimental values, while the most inaccurate results were obtained by either of Zhang et al. methods. More than half of the estimates obtained by these methods deviate at least $30 \%$ from corresponding experimental values. 
Overall evaluation for all steels provided averaged results as was the case for estimates of $R_{\mathrm{e}}$. Lopez and Fatemi 1 method is the most accurate while both Zhang et al. methods are least successful, as was the case for individual steel subgroups.

\section{Discussion}

Estimation methods investigated in this paper were developed on datasets comprising all steels [11-13], and even some other groups of metallic materials (steels, aluminium and titanium alloys) [10]. However, in order to improve accuracy of estimations, most methods propose some criterion for grouping of materials. In [12,13] authors divided steels by rather easily available $R_{\mathrm{m}} / R_{\mathrm{e}}$ ratio. In [10], grouping criteria used was the new fracture ductility parameter $\alpha$, which is cumbersome to use since true fracture stress $\varepsilon_{\mathrm{f}}$ or reduction of area $R A$ needed for its calculation are often unavailable.

Much more usable, and often encountered in practice, is division of steels by their alloying content into unalloyed, low-alloy and high-alloy steels. It was shown in $[6,8,15-17]$ that dividing steels in this manner contributes to improvement of estimations of steel behavior from monotonic properties of steels. Results of analysis performed in Section 4.1 confirmed that statistically significant differences exist between cyclic yield stress $R_{\mathrm{e}}{ }^{\prime}$ and cyclic parameters $K^{\prime}$ and $n^{\prime}$ of mentioned group of steels. According to these findings, authors propose evaluation of existing methods for estimation of $R_{\mathrm{e}}{ }^{\prime}, K^{\prime}$ and $n^{\prime}$ to be performed for each group individually, in addition to all steels together.

For estimation of $R_{\mathrm{e}}{ }^{\prime}, K^{\prime}$ and $n^{\prime}$ of both unalloyed and low-alloy steels, methods by Lopez and Fatemi [12], and by Li et al. [13] provide very good results. However, estimations for high-alloy steels are notably worse, especially those obtained using the Li et al. method which is not surprising since both methods are developed on the same set of data, consisting mostly of unalloyed and low-alloy steels.

Values of $K^{\prime}$ and $n^{\prime}$ estimated with two methods developed by Zhang et al. [10], are generally unsatisfactory and provide poor results for all steel subgroups, especially high-alloy steels. This can be attributed to the fact that methods were developed on a modest number (22) of heterogeneous data (steels, aluminium and titanium alloys). Another drawback of methods proposed by Zhang et al. are intricate expressions requiring monotonic properties which are often unavailable, especially during the early stages of product development.

Evaluations of existing methods in original references are performed for all materials together. Also, in some cases, evaluation of existing methods is performed on the same sets of data that were used for development of the method-a practice which can be considered less than objective.

Results of evaluations strongly depend on structure and amount of data available. Proposed consideration of individual subgroups provides valuable additional information. Figure 3 shows that, although methods by Lopez and Fatemi and Li et al. are suitable for all steels, individual results for unalloyed and low-alloy steels are even better.

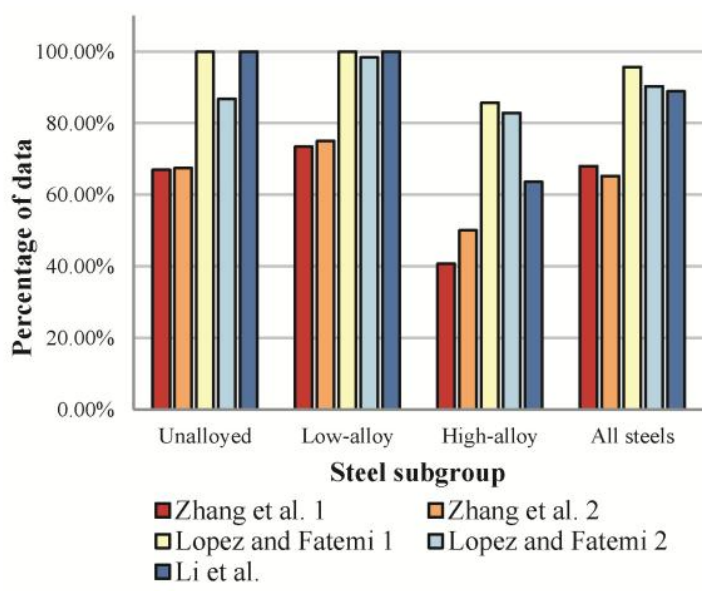

Figure 3. Percentage of estimates of $\Delta \sigma / 2$ deviating up to $30 \%$ from experimental values. 
As mentioned earlier, this was expected since the similar set of data, consisting of mostly unalloyed and low-alloy steels, was used in both papers. If only results for all steels group were observed, information about lower accuracy for high-alloy steels would go unnoticed, particularly for the method by Li et al. This example shows how evaluations of estimation methods performed for all steels together could be misinterpreted due to averaging.

Table 2 provides recommended methods for estimation of cyclic parameters of each group of steels, noting that great care is advised when estimating cyclic parameters of high-alloy steels. Ordinal number preceding the method indicates suggested selection priority. In cases where multiple methods are given without order simpler methods requiring a smaller number of monotonic properties (such as methods by Lopez and Fatemi) might be preferred.

Table 2. Recommended methods for estimation of cyclic yield stress $R_{\mathrm{e}}{ }^{\prime}$ and cyclic parameters $K^{\prime}$ and $n^{\prime}$ of steels.

\begin{tabular}{ccc}
\hline Steel Subgroup & Estimation of $\boldsymbol{R}_{\mathbf{e}}{ }^{\prime}$ & Estimation of $\Delta \boldsymbol{\sigma} / \mathbf{2}\left(\boldsymbol{K}^{\prime}, \boldsymbol{n}^{\prime}\right)$ \\
\hline Unalloyed steels & Li et al. & 1. Li et al. \\
& Lopez and Fatemi 2 & 2. Lopez and Fatemi 1 \\
\hline \multirow{2}{*}{ Low-alloy steels } & 1. Lopez and Fatemi 1 & Lopez and Fatemi 1 \\
& 2. Li et al. & Lopez and Fatemi 2 \\
& 3. Lopez and Fatemi 2 & Li et al. \\
\hline High-alloy steels & Lopez and Fatemi 1 & Lopez and Fatemi 1 \\
\hline
\end{tabular}

\section{Conclusions}

Available methods for estimation of cyclic yield stress $R_{\mathrm{e}}{ }^{\prime}$ and cyclic stress-strain parameters $K^{\prime}$ and $n^{\prime}$ of steels and their applicability to individual steel subgroups and to steels as a general group were studied. A large, independent set of steel data was collected in order to perform the study as it was shown that number and type of materials used for development of estimation methods have significant influence on their performance and evaluation results.

Statistically significant differences were determined to exist among unalloyed, low-alloy and high-alloy steels regarding their cyclic stress-strain behavior and parameters. Such division of steels based on their content of alloying elements is also commonly encountered in practice, so it was used for performed evaluation of studied estimation methods.

Comparison of values of stress amplitudes $\Delta \sigma / 2$ calculated using experimental and estimated cyclic parameters $\left(K^{\prime}\right.$ and $\left.n^{\prime}\right)$ is proposed as a more suitable criterion for evaluation instead of direct comparison of corresponding individual cyclic parameters $R_{\mathrm{e}}{ }^{\prime}, K^{\prime}$ and $n^{\prime}$.

Having all steels in a single group for evaluation purposes causes significant averaging of the results so unalloyed, low-alloy and high-alloy steels were treated separately. Considerable differences were determined in accuracy and applicability of different methods for different steel subgroups.

For estimations of $R_{\mathrm{e}}{ }^{\prime}$ of unalloyed and low-alloy steels methods proposed by $\mathrm{Li}$ et al. and Lopez and Fatemi were found to provide very good results, while for high-alloy steels, only the method dividing steels by $R_{\mathrm{e}} / R_{\mathrm{m}}$ ratio proposed by Lopez and Fatemi provides reasonably accurate estimates. The method for estimations of $K^{\prime}$ and $n^{\prime}$ of unalloyed steels proposed by Li et al. gives the best estimates followed closely by the Lopez and Fatemi method which considers the $R_{\mathrm{e}} / R_{\mathrm{m}}$ ratio. For low-alloy steels, both methods by Lopez and Fatemi and the method by Li et al. provide excellent results. Of all methods, only the method proposed by Lopez and Fatemi considering the $R_{e} / R_{\mathrm{m}}$ ratio can be considered for use with the high-alloy steels group.

Estimation accuracy of all studied methods for $R_{\mathrm{e}}{ }^{\prime}, K^{\prime}$ and $n^{\prime}$ was notably lower for high-alloy steels in comparison to other two subgroups, which can be attributed to the fact that high-alloy steels were found to be underrepresented in material datasets used for development of estimation methods. 
Acknowledgments: This work has been supported in part by the University of Rijeka (projects number 13.09.1.2.09 and 13.09.2.2.18) and Croatian Science Foundation (scientific project number IP-2014-09-4982).

Author Contributions: R.B. and T.M. conceived and formulated the research; R.B., T.M. and M.F. acquired and systematized the material data, T.M. systematized and reviewed the estimation methods; T.M. designed and performed statistical analysis; T.M. and R.B., with the support of M.F., evaluated and interpreted estimation results; T.M., with the support of R.B. and M.F., prepared the manuscript. All co-authors contributed to the manuscript proof and submission.

Conflicts of Interest: The authors declare no conflict of interest. The founding sponsors had no role in the design of the study; in the collection, analyses, or interpretation of data; in the writing of the manuscript, and in the decision to publish the results.

\section{Appendix A}

Detailed material data used for analysis in this paper are given in Tables A1-A3.

Table A1. Monotonic and cyclic properties for unalloyed steels $[6,23,24]$.

\begin{tabular}{|c|c|c|c|c|c|c|c|c|c|c|c|c|}
\hline Material Designation & \multicolumn{9}{|c|}{ Monotonic Properties } & \multicolumn{3}{|c|}{ Cyclic Parameters } \\
\hline DIN or SAE/other & $\sum_{\omega}^{\circlearrowright}$ & 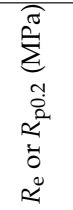 & 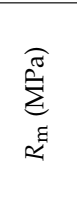 & $\begin{array}{l}I \\
\stackrel{I}{\Sigma} \\
\stackrel{\Sigma}{\Sigma}\end{array}$ & 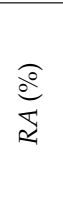 & $\sum_{\mathbb{V}}^{\infty}$ & $\stackrel{I}{I}$ & $\sum_{\vec{b}}^{\infty}$ & $\underset{\vec{\omega}}{I}$ & $\sum_{\tilde{\Sigma}}^{\infty}$ & $\sum_{\Sigma}^{\infty}$ & II \\
\hline 1038 (SAE) & 207,000 & 347 & 610 & 1.758 & 55.5 & 511 & 0.071 & 956 & 0.590 & 332 & 1207 & 0.208 \\
\hline Armco (other) & 210,000 & 207 & 359 & 1.734 & 64 & 675 & 0.285 & 653 & 1.030 & 280 & 858 & 0.18 \\
\hline C 20 & 190,000 & 224 & 414 & 1.848 & 70 & 330 & 0.061 & 953 & 1.190 & 239 & 1050 & 0.238 \\
\hline C 10 & 217,510 & 435 & 566 & 1.301 & 68 & 659 & 0.073 & 1205 & 1.130 & 463 & 1381 & 0.176 \\
\hline Ck 15 & 196,793 & 263 & 392 & 1.490 & 55 & 711 & 0.224 & 746 & 0.806 & 249 & 824 & 0.193 \\
\hline Ck 15 & 204,500 & 320 & 434 & 1.356 & 67.5 & 394 & 0.067 & 848.7 & 1.126 & 269 & 813 & 0.178 \\
\hline Ck 15 & 202,000 & 431.3 & 615.2 & 1.426 & 54 & 598 & 0.045 & 1011.7 & 0.776 & 492 & 1296 & 0.156 \\
\hline Ck 15 & 203,000 & 660 & 828 & 1.255 & 2.6 & 863 & 0.042 & 850.5 & 0.026 & 687 & 1165 & 0.085 \\
\hline Ck 25 & 210,000 & 346 & 507 & 1.465 & 63 & 926 & 0.264 & 1027 & 0.994 & 280 & 1345 & 0.252 \\
\hline Ck 25 & 210,000 & 307 & 464 & 1.511 & 65 & 924 & 0.276 & 982 & 1.050 & 278 & 1111 & 0.223 \\
\hline Ck 25 & 210,000 & 366 & 527 & 1.440 & 60 & 1033 & 0.264 & 997 & 0.916 & 303 & 1217 & 0.224 \\
\hline Ck 35 & 210,000 & 414 & 617 & 1.490 & 58 & 1216 & 0.258 & 1150 & 0.868 & 328 & 1355 & 0.229 \\
\hline Ck 35 & 210,000 & 394 & 593 & 1.505 & 62 & 1168 & 0.257 & 1169 & 0.968 & 333 & 1460 & 0.238 \\
\hline Ck 35 & 210,000 & 396 & 565 & 1.427 & 63 & 1134 & 0.264 & 1134 & 0.994 & 316 & 1534 & 0.254 \\
\hline Ck 35 & 210,000 & 587 & 780 & 1.329 & 67 & 1356 & 0.186 & 1514 & 1.109 & 463 & 1106 & 0.14 \\
\hline Ck 35 & 210,000 & 480 & 656 & 1.367 & 74 & 1196 & 0.207 & 1468 & 1.347 & 393 & 1033 & 0.156 \\
\hline Ck 35 & 210,000 & 596 & 733 & 1.230 & 71 & 1170 & 0.152 & 1541 & 1.238 & 447 & 1027 & 0.134 \\
\hline Ck 35 & 210,000 & 542 & 730 & 1.347 & 68 & 1311 & 0.2 & 1473 & 1.139 & 430 & 1087 & 0.149 \\
\hline Ck 35 & 210,000 & 513 & 669 & 1.304 & 70 & 1121 & 0.18 & 1417 & 1.204 & 387 & 1081 & 0.165 \\
\hline Ck 45 & 206,000 & 540 & 790 & 1.463 & 60 & 730 & 0.047 & 1400 & 0.916 & 481 & 980 & 0.115 \\
\hline Ck 45 & 210,500 & 531 & 790 & 1.488 & 60 & 1219 & 0.0151 & 1271 & 0.777 & 462 & 1078 & 0.133 \\
\hline Ck 45 & 199,700 & 622 & 915 & 1.471 & 59 & 1606 & 0.18 & 1784 & 0.900 & 591 & 2407 & 0.226 \\
\hline Ck 45 & 199,700 & 622 & 915 & 1.471 & 59 & 1606 & 0.18 & 1784 & 0.900 & 538 & 1762 & 0.191 \\
\hline Ck 45 & 201,500 & 380 & 684 & 1.800 & 36.8 & 735 & 0.092 & 987 & 0.460 & 336 & 1414 & 0.231 \\
\hline Ck 45 & 205,000 & 760 & 1018 & 1.339 & 0 & 1141 & 0.059 & 1018 & 0.000 & 722 & 2075 & 0.17 \\
\hline Ck 45 & 199,000 & 466 & 737 & 1.582 & 54 & 1469 & 0.248 & 1296 & 0.777 & 368 & 1486 & 0.225 \\
\hline Ck 45 & 207,000 & 462 & 672 & 1.455 & 61 & 1288 & 0.235 & 1298 & 0.942 & 354 & 1391 & 0.22 \\
\hline Ck 45 & 208,000 & 588 & 730 & 1.241 & 70 & 1154 & 0.148 & 1540 & 1.204 & 420 & 1194 & 0.168 \\
\hline Ck 45 & 207,000 & 551 & 774 & 1.405 & 68 & 1297 & 0.166 & 1559 & 1.139 & 464 & 1235 & 0.158 \\
\hline Ck 45 & 206,000 & 728 & 844 & 1.159 & 64 & 1208 & 0.108 & 1582 & 1.022 & 516 & 1217 & 0.138 \\
\hline Ck 45 & 210,000 & 652 & 787 & 1.207 & 68 & 1200 & 0.129 & 1568 & 1.139 & 472 & 1285 & 0.161 \\
\hline Ck 45 & 204,000 & 702 & 863 & 1.229 & 66 & 1268 & 0.118 & 1651 & 1.079 & 526 & 1243 & 0.138 \\
\hline St 37 & 210,000 & 295 & 435 & 1.475 & 64 & 829 & 0.275 & 835 & 1.020 & 273 & 988 & 0.207 \\
\hline St $52-3$ & 210,000 & 400 & 597 & 1.493 & 63 & 1061 & 0.225 & 1083 & 0.980 & 389 & 1228 & 0.185 \\
\hline
\end{tabular}

Note: Shaded values are calculated by Equation (20). 
Table A2. Monotonic and cyclic properties for low-alloy steels $[6,23,24]$.

\begin{tabular}{|c|c|c|c|c|c|c|c|c|c|c|c|c|}
\hline Material Designation & \multicolumn{9}{|c|}{ Monotonic Properties } & \multicolumn{3}{|c|}{ Cyclic Parameters } \\
\hline DIN & $\sum_{\omega}^{\pi}$ & 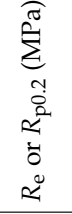 & 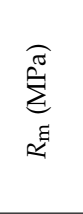 & $\begin{array}{l}I \\
\cong \\
\approx \\
\approx \\
\approx\end{array}$ & $\frac{a}{d}$ & $\sum_{i}^{\infty}$ & $\stackrel{I}{I}$ & 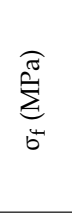 & $\underbrace{I}_{\omega^{ \pm}}$ & 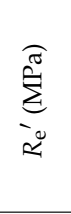 & $\sum_{i}^{\overparen{E}}$ & $\begin{array}{l}I \\
I\end{array}$ \\
\hline $100 \mathrm{Cr} 6$ & 207,000 & 1927 & 2016 & 1.046 & 12 & 2281 & 0.031 & 2230 & 0.120 & 1341 & 3328 & 0.146 \\
\hline 11 NiMnCrMo 55 & 210,000 & 745 & 852 & 1.144 & 57 & 1277 & 0.124 & 1327 & 0.834 & 663 & 1145 & 0.088 \\
\hline $14 \mathrm{Mn} 5$ & 206,000 & 580 & 697 & 1.202 & 68 & 858 & 0.067 & 1222 & 1.150 & 537 & 1436 & 0.158 \\
\hline 16 NiCrMo 32 & 209,000 & 891 & 939 & 1.054 & 63 & 963 & 0.011 & 1491 & 0.994 & 617 & 1080 & 0.09 \\
\hline 17 MnCrMo 33 & 214,000 & 833 & 929 & 1.115 & 58 & 1285 & 0.099 & 1446 & 0.867 & 663 & 1252 & 0.102 \\
\hline $20 \mathrm{Mn} 3$ & 206,000 & 910 & 960 & 1.055 & 43 & 1190 & 0.06 & 1090 & 0.561 & 675 & 1313 & 0.107 \\
\hline $22 \mathrm{MnCrNi} 3$ & 198,000 & 1200 & 1510 & 1.258 & 42 & 2447 & 0.114 & 2034 & 0.549 & 1046 & 2149 & 0.112 \\
\hline $22 \mathrm{MnCrNi} 3$ & 195,000 & 1200 & 1586 & 1.322 & 3 & 2586 & 0.115 & 1669 & 0.026 & 1193 & 2759 & 0.135 \\
\hline $23 \mathrm{Mn} 4$ & 207,000 & 1008 & 1091 & 1.082 & 61 & 1185 & 0.026 & 1616 & 0.950 & 656 & 1616 & 0.145 \\
\hline $23 \mathrm{NiCr} 4$ & 208,531 & 725 & 808 & 1.114 & 66 & 762 & 0.007 & 1215 & 1.080 & 541 & 1221 & 0.131 \\
\hline $25 \mathrm{Mn} 3$ & 200,000 & 351 & 540 & 1.538 & 67 & 992 & 0.236 & 1173 & 1.100 & 322 & 1219 & 0.214 \\
\hline $25 \mathrm{Mn} 5$ & 207,000 & 904 & 1008 & 1.115 & 49 & 1138 & 0.033 & 1284 & 0.680 & 608 & 1900 & 0.183 \\
\hline $28 \mathrm{MnCu} 6$ & 204,000 & 330 & 580 & 1.758 & 64 & 938 & 0.19 & 950 & 1.030 & 347 & 1151 & 0.193 \\
\hline 30 CrMo 2 & 221,000 & 780 & 898 & 1.151 & 67 & 1117 & 0.063 & 1692 & 1.120 & 579 & 1366 & 0.138 \\
\hline 30 CrMo 2 & 200,250 & 1360 & 1429 & 1.051 & 55 & 1661 & 0.033 & 2085 & 0.790 & 814 & 1758 & 0.124 \\
\hline 30 CrMoNiV 511 & 212,000 & 605 & 773 & 1.278 & 62 & 717 & 0.027 & 1332 & 0.968 & 497 & 894 & 0.094 \\
\hline 30 CrNiMo 8 & 206,000 & 700 & 910 & 1.300 & 66 & 1128 & 0.079 & 1168 & 0.708 & 573 & 972 & 0.085 \\
\hline 30 CrNiMo 8 & 206,000 & 700 & 910 & 1.300 & 66 & 1128 & 0.079 & 1168 & 0.708 & 522 & 995 & 0.095 \\
\hline $30 \mathrm{MnCr} 5$ & 206,000 & 820 & 950 & 1.159 & 64 & 1250 & 0.097 & 1445 & 1.068 & 576 & 1618 & 0.166 \\
\hline $34 \mathrm{CrMo} 4$ & 193,000 & 1017 & 1088 & 1.070 & 65 & 1344 & 0.056 & 1903 & 1.050 & 692 & 1310 & 0.103 \\
\hline $34 \mathrm{CrMo} 4$ & 188,000 & 847 & 939 & 1.109 & 69 & 1215 & 0.074 & 1795 & 1.171 & 624 & 1008 & 0.077 \\
\hline $34 \mathrm{CrMo} 4$ & 190,000 & 893 & 978 & 1.095 & 67 & 1338 & 0.089 & 1787 & 1.109 & 650 & 987 & 0.067 \\
\hline $34 \mathrm{CrMo} 4$ & 197,000 & 980 & 1078 & 1.100 & 61 & 1382 & 0.07 & 1818 & 0.942 & 711 & 1373 & 0.106 \\
\hline $34 \mathrm{CrMo} 4$ & 194,000 & 780 & 881 & 1.129 & 71 & 1299 & 0.116 & 1740 & 1.238 & 556 & 1198 & 0.124 \\
\hline 4 NiCrMn 4 & 206,000 & 454 & 623 & 1.372 & 76 & 753 & 0.081 & 1229 & 1.450 & 505 & 1111 & 0.127 \\
\hline 40 CrMo 4 & 208,780 & 840 & 940 & 1.119 & 64 & 1300 & 0.094 & 1440 & 1.035 & 583 & 1307 & 0.13 \\
\hline 40 NiCrMo 6 & 201,000 & 1084 & 1146 & 1.057 & 59 & 1549 & 0.083 & 1857 & 0.890 & 758 & 1550 & 0.115 \\
\hline 40 NiCrMo 6 & 190,000 & 910 & 1015 & 1.115 & 62 & 1372 & 0.089 & 1808 & 0.970 & 660 & 1392 & 0.12 \\
\hline 40 NiCrMo 6 & 202,000 & 953 & 1029 & 1.080 & 62 & 1448 & 0.1 & 1724 & 0.970 & 659 & 1628 & 0.145 \\
\hline 40 NiCrMo 6 & 193,000 & 998 & 1067 & 1.069 & 62 & 1474 & 0.092 & 1761 & 0.970 & 716 & 1292 & 0.095 \\
\hline 40 NiCrMo 6 & 205,000 & 810 & 884 & 1.091 & 67 & 1378 & 0.142 & 1680 & 1.110 & 586 & 1303 & 0.129 \\
\hline $40 \mathrm{NiCrMo} 7$ & 193,500 & 1374 & 1471 & 1.071 & 38 & 1796 & 0.04 & 1920 & 0.480 & 905 & 1890 & 0.118 \\
\hline $40 \mathrm{NiCrMo} 7$ & 193,500 & 635 & 829 & 1.306 & 43 & 1175 & 0.098 & 1201 & 0.570 & 474 & 1332 & 0.167 \\
\hline $41 \mathrm{MnCr} 34$ & 207,280 & 800 & 930 & 1.163 & 62 & 1350 & 0.112 & 1390 & 0.960 & 551 & 1340 & 0.143 \\
\hline $42 \mathrm{Cr} 4$ & 195,000 & 903 & 1006 & 1.114 & 62 & 1293 & 0.068 & 1716 & 0.968 & 679 & 1153 & 0.085 \\
\hline $42 \mathrm{Cr} 4$ & 194,000 & 813 & 921 & 1.133 & 65 & 1249 & 0.086 & 1674 & 1.050 & 613 & 1147 & 0.101 \\
\hline $42 \mathrm{Cr} 4$ & 194,000 & 845 & 952 & 1.127 & 62 & 1288 & 0.086 & 1689 & 0.968 & 619 & 1207 & 0.107 \\
\hline $42 \mathrm{Cr} 4$ & 192,000 & 833 & 943 & 1.132 & 65 & 1289 & 0.09 & 1690 & 1.050 & 621 & 1192 & 0.105 \\
\hline 42 Cr 4 & 193,000 & 717 & 840 & 1.172 & 69 & 1240 & 0.118 & 1617 & 1.171 & 543 & 1161 & 0.122 \\
\hline $42 \mathrm{CrMo} 4$ & 211,400 & 998 & 1111 & 1.113 & 60 & 1469 & 0.069 & 1525 & 0.496 & 716 & 1367 & 0.104 \\
\hline 49 MnVS 3 & 210,200 & 566 & 840 & 1.484 & 19 & 1428 & 0.194 & 1152 & 0.380 & 520 & 1396 & 0.159 \\
\hline $50 \mathrm{CrMo} 4$ & 205,000 & 970 & 1086 & 1.120 & 48.6 & 1132 & 0.026 & 1609 & 0.665 & 700 & 1568 & 0.13 \\
\hline $50 \mathrm{CrMo} 4$ & 205,000 & 947 & 983 & 1.038 & 14.6 & 1042 & 0.018 & 926 & 0.157 & 774 & 1754 & 0.132 \\
\hline 8 Mn 6 & 198,000 & 862 & 965 & 1.119 & 57 & 1227 & 0.054 & 1579 & 0.850 & 580 & 1256 & 0.125 \\
\hline $8 \mathrm{Mn} 6$ & 198,000 & 821 & 869 & 1.058 & 53 & 1085 & 0.046 & 1434 & 0.750 & 674 & 1258 & 0.101 \\
\hline $80 \mathrm{Mn} 4$ & 187,500 & 502 & 931 & 1.855 & 16 & 1100 & 0.127 & 1060 & 0.174 & 459 & 1859 & 0.225 \\
\hline WStE 460 & 210,000 & 560 & 667 & 1.191 & 61 & 1096 & 0.153 & 1171 & 0.932 & 514 & 1194 & 0.128 \\
\hline
\end{tabular}


Table A3. Monotonic and cyclic properties for high-alloy steels $[6,23,24]$.

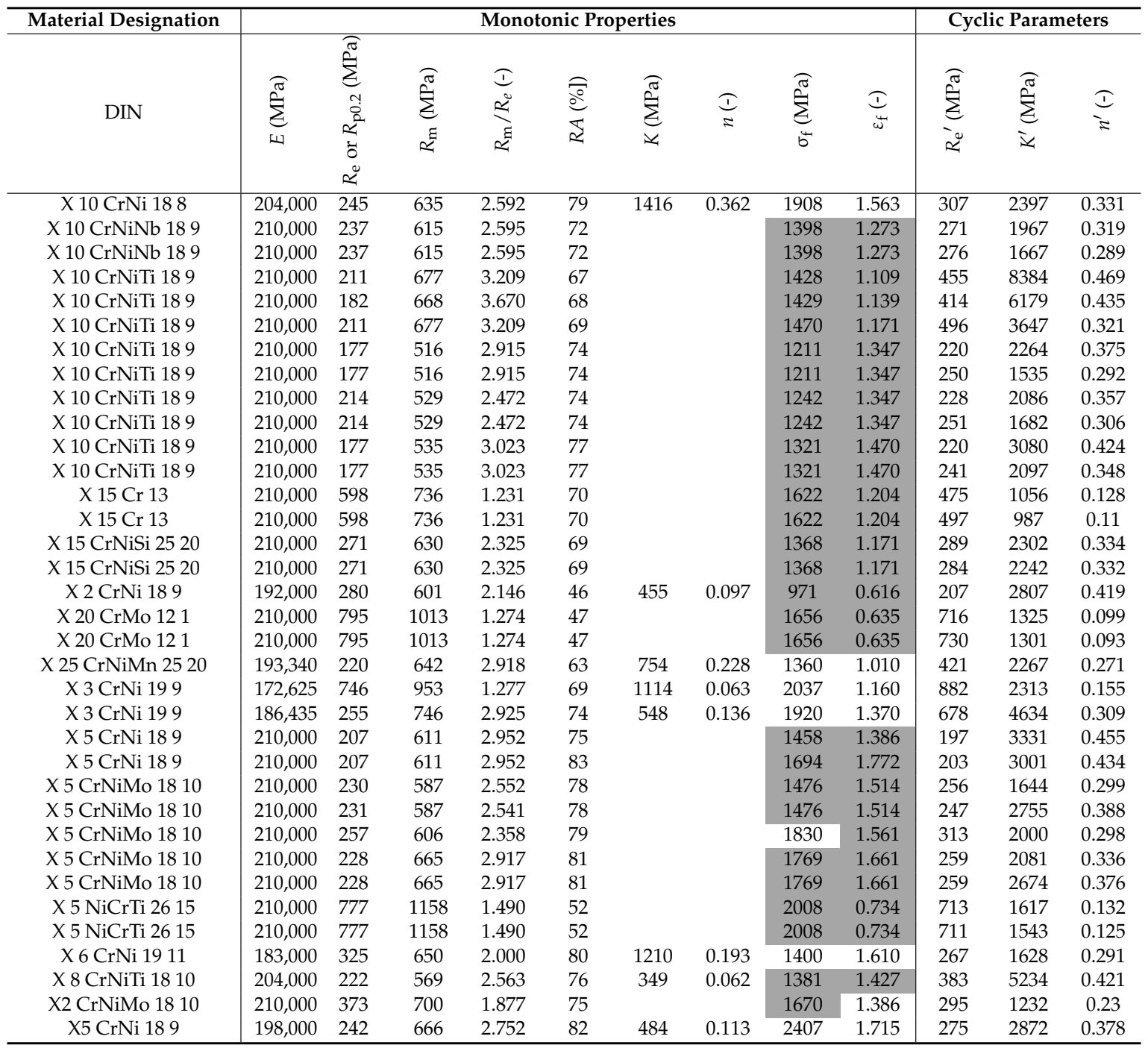

Note: Shaded values are calculated by Equations (8) and (20).

\section{References}

1. Williams, C.R.; Lee, Y.-L.; Rilly, J.T. A practical method for statistical analysis of strain-life fatigue data. Int. J. Fatigue 2003, 25, 427-436. [CrossRef]

2. Blackmore, P.A. A critical review of Baumel-Seeger method for estimating strain-life fatigue properties of metallic materials. Eng. Integr. 2009, 27, 6-11.

3. Ramberg, W.; Osgood, W.R. Description of Stress-Strain Curves by Three Parameters; Technical Note No. 902; National Advisory Committee for Aeronautics (NACA): Washington, DC, USA, 1943.

4. Manson, S.S.; Halford, G.R. Fatigue and Durability of Structural Materials, 1st ed.; ASM International: Materials Park, OH, USA, 2005.

5. Manson, S.S. Fatigue: A complex subject-Some simple approximations. Exp. Mech. SESA 1965, 5, $193-226$. [CrossRef]

6. Bäumel, A., Jr.; Seeger, T. Materials Data for Cyclic Loading-Supplement 1, 1st ed.; Elsevier: Amsterdam, The Netherlands, 1990.

7. Roessle, M.L.; Fatemi, A. Strain-controlled fatigue properties of steels and some simple approximations. Int. J. Fatigue 2000, 22, 495-511. [CrossRef]

8. Hatscher, A.; Seeger, T.; Zenner, H. Abschätzung von zyklischen Werkstoffkennwerten-Erweiterung und Vergleich bisheriger Ansätze. Materialprufung 2007, 49, 2-14. 
9. Park, J.H.; Song, J.H. Detailed evaluation of methods for estimation of fatigue properties. Int. J. Fatigue 1995, 17, 365-373. [CrossRef]

10. Zhang, Z.; Qiao, Y.; Sun, Q.; Li, C.; Li, J. Theoretical estimation to the cyclic strength coefficient and the cyclic strain-hardening exponent for metallic materials: Preliminary study. J. Mater. Eng. Perform. 2009, 18, $245-254$. [CrossRef]

11. Li, J.; Sun, Q.; Zhang, Z.; Li, C.; Qiao, Y. Theoretical estimation to the cyclic yield strength and fatigue limit for alloy steels. Mech. Res. Commun. 2009, 36, 316-321. [CrossRef]

12. Lopez, Z.; Fatemi, A. A method of predicting cyclic stress-strain curve from tensile properties for steels. Mater. Sci. Eng. A Struct. 2012, 556, 540-550. [CrossRef]

13. Li, J.; Zhang, Z.; Li, C. An improved method for estimation of Ramberg-Osgood curves of steels from monotonic tensile properties. Fatigue Fract. Eng. Mater. Struct. 2016, 39, 412-426. [CrossRef]

14. Marohnić, T.; Basan, R. Study of Monotonic Properties' Relevance for Estimation of Cyclic Yield Stress and Ramberg-Osgood Parameters of Steels. J. Mater. Eng. Perform. 2016, 25, 4812-4823. [CrossRef]

15. Basan, R.; Franulović, M.; Prebil, I.; Črnjarić-Žic, N. Analysis of strain-life fatigue parameters and behavior of different groups of metallic materials. Int. J. Fatigue 2011, 33, 484-491. [CrossRef]

16. Basan, R.; Marohnić, T.; Prebil, I.; Franulović, M. Preliminary investigation of the existence of correlation between cyclic Ramberg-Osgood parameters and monotonic properties of low-alloy steels. In Proceedings of the 3rd International Conference Mechanical Technologies and Structural Materials MTSM 2013, Split, Croatia, 26-27 September 2013; Živković, D., Ed.; Croatian society for mechanical technologies: Split, Croatia, 2013.

17. Marohnić, T.; Basan, R.; Franulović, M. Evaluation of the Possibility of Estimating Cyclic Stress-strain Parameters and Curves from Monotonic Properties of Steels. Procedia Eng. 2015, 101, 277-284. [CrossRef]

18. Smith, R.W.; Hirschberg, M.H.; Manson, S.S. Fatigue Behavior of Materials under Strain Cycling in Low and Intermediate Life Range; Technical Note D-1574; National Aeronautics and Space Administration (NASA): Washington, DC, USA, 1963.

19. Zhang, Z.; Wu, W.; Chen, D.; Sun, Q.; Zhao, W. New Formula Relating the Yield Stress-Strain with the Strength Coefficient and the Strain-Hardening Exponent. J. Mater. Eng. Perform. 2004, 13, 509-512.

20. Landgraf, R.W.; Morrow, J.; Endo, T. Determination of cyclic stress-strain curve. J. Mater. 1969, 4, $176-188$.

21. Devore, J. Probability and Statistics for Engineering and the Sciences; Brooks/Cole Cengage Learning: Boston, MA, USA, 2011.

22. Minitab 17 Statistical Software, Product version 17.3.1; Computer Software; Minitab, Inc.: State College, PA, USA, 2010.

23. Boller, C.; Seeger, T. Materials Data for Cyclic Loading, Part A-D, 1st ed.; Elsevier: Amsterdam, The Netherlands, 1987.

24. Basan, R. MATDAT Materials Properties Database, Version 1.1. 2011. Available online: http:/ /www.matdat.com/ (accessed on 15 January 2016). 